\title{
Factors for Social Stressors Among Type 2 Diabetics Versus Non-Diabetics Using the Hamilton Depression Rating Scale
}

\author{
Saadia Y. Raja ${ }^{1}$, Uzma Ghori $^{1}$, Haider Ali Naqvi ${ }^{2}$, Sadaf Aijaz ${ }^{3}$, Adnan Anwar ${ }^{4}$, Atif A. Hashmi ${ }^{5}$ \\ 1. Internal Medicine, Ziauddin University, Karachi, PAK 2. Psychiatry, Ziauddin University, Karachi, PAK 3. Psychiatry, \\ Northern Border University, Arar, SAU 4. Physiology, Al-Tibri Medical College, Isra University, Karachi, PAK 5. \\ Pathology, Liaquat National Hospital and Medical College, Karachi, PAK
}

Corresponding author: Atif A. Hashmi, atifhashmi345@gmail.com

\section{Abstract \\ Objective}

This study aimed to evaluate different factors of social stressors among people with type II diabetes versus non-diabetics by using the Hamilton Depression Rating Scale (HAM-D).

\section{Methodology}

This case-control study was done for one year at Ziauddin University Hospital, Karachi, Pakistan. Diagnosed patients with type II diabetes between 25 and 60 years were included as cases and age-related healthy individuals as controls. Participants on any psychotropic medications, neurodegenerative disorders, or on chemotherapy were excluded. Hamilton Rating Scale for Depression (HRDS-17) was used for recording depressive symptoms. The Statistical Package for the Social Sciences (SPSS) version 26.0 (IBM Corp., Armonk, NY) was used for data analysis. The frequency was calculated for descriptive statistics and depression scores (HRDS-17). A significance level of 0.05 was considered.

\section{Results}

A total of 272 patients were divided into two groups, with 136 patients in the group with diabetes and 136 participants in the control group. The mean age among people with diabetes was $55.13 \pm 9.10$ years and among non-diabetics was $43.25 \pm 12.97$ years $(\mathrm{p}<0.001)$. The mean duration of illness in people with diabetes was $8.51 \pm 7.57$ years and in non-diabetics, it was $6.73 \pm 4.42$ years $(\mathrm{p}=0.018)$. The mean social rating in people with diabetes was $164.0 \pm 155.60$ and in non-diabetics, it was $124.75 \pm 99.02(\mathrm{p}=0.014)$. Insomnia, both in the early and middle part of the night affecting work activities, hypochondriasis, and loss of weight, was significantly present among diabetics as compared to controls $(\mathrm{p}<0.05)$.

\section{Conclusion}

Review began $11 / 18 / 2020$ Review ended 11/19/2020 Published 12/02/2020

\section{(๑) Copyright 2020}

Raja et al. This is an open access article distributed under the terms of the Creative Commons Attribution License CC-BY 4.0., which permits unrestricted use, distribution, and reproduction in any medium, provided the original author and source are credited.
Most diabetics reported a significant effect on the quality of life based on social rating and health-care expenditure. They experienced depressive symptoms more frequently than non-diabetics. Insomnia in the middle of the night affected work and activities; hypochondriasis and weight loss were found to be substantially higher among patients with diabetes than in controls.

Categories: Endocrinology/Diabetes/Metabolism, Internal Medicine, Psychiatry

Keywords: social stressors, depression, anxiety, type ii diabetes, hamilton depression rating scale (ham-d)

\section{Introduction}

The ever-increasing incidences of stress, anxiety, and depression among patients of type II diabetes mellitus (type II DM) are alarming as compared with the general population [1]. Type II DM is termed as a chronic illness, which is hazardous to health all over the globe, resulting in a significant disorder of lifestyle having a potential short and long-term incidence of complications. Alternatively, depression is one of the most commonly reported psychological disorders [2]. Patients with type II DM have been known to develop depression, therefore leading to unfavorable or worse outcomes. Type II DM causes a substantial burden on both medical and economic forums. Between 2010 and 2030, an approximately 69\% increase in type II DM among adults has been estimated while it is approximately $20 \%$ in developed countries [3-4]. Nevertheless, the risk factors of both type II DM and depression are modifiable even when they occur as a long-term disorder. Type II DM is the leading cause of death, affecting around 264 million people worldwide [5].

In Pakistan, the prevalence of type II DM in the urban population above the age of 25 years is approximately $6.8 \%$ for males and $5.1 \%$ for females; the rates are lower in the rural community, i.e., $5 \%$ in males and $4.8 \%$ in females [6]. The worldwide prevalence of depression, both in the developed and developing worlds, is estimated to be $10 \%$. Simultaneously, this frequency is reported to be much higher in Pakistan, 
approximately 34\%, including both urban and rural diabetic populations [7]. In the rural community of Pakistan, rates of depression were recorded at $14.7 \%$ among patients with diabetes. Type II DM is linked with depression, leading to deterioration in the quality of life and substantially affecting compliance to treatment of both type II DM and depression. Losing interest in maintaining one's health, as well as dietary regimen or exercise, is commonly observed among patients with depression [8].

Type II DM can predispose a person to stress and depression, lowering his/her quality of life in terms of maintaining good health. The fear of depression's occurrence among patients with type II DM leads to not only a functional and financial but also a psychological burden on the person as well as his/her family, leading to poor glycemic control, noncompliance with medication, and worsening adherence with diet, exercise, and self-care [9-10].

Proper guidelines for an appropriate approach toward patients with type II DM with stress or depression and those without stress or depression are still under consideration and a matter of debate. The condition is termed as stress linked to diabetes. Combining type II DM with psychiatric disorders, such as depression, substance abuse, and anxiety, with reduced quality of life, leads to higher chances of hyperglycemia. All these conditions lead to significant difficulties in regulating blood glucose [11-12]. Therefore, they make patients with type II DM susceptible to diabetic and psychiatric complications. Studies have reported that among diabetic patients with depression, the use of medicines is recommended along with physical activity for increasing treatment effectiveness, as it leads to the release of B-endorphins and cerebral neurotransmitters. In turn, this decreases levels of stress and anxiety, which results in an improvement in the quality of life of these patients [13-14].

Therefore, this study aimed to evaluate the different factors of social stressors among people with type II diabetes as compared to non-diabetics by using the Hamilton Depression Rating Scale (HAM-D).

\section{Materials And Methods}

This case-control study was conducted at Ziauddin University Hospital, Karachi, Pakistan. The sampling technique was consecutive and the duration of the study was six months from January 2020 until May 2020. Diagnosed patients with type II diabetes between the ages of 25 and 60 years, having documented glycated hemoglobin (HbA1c) levels $>6.5 \%$ or two reported random blood glucose levels of more than $200 \mathrm{mg} / \mathrm{dl}$ and on oral hypoglycemic drug/insulin treatment for a minimum of six months were included as the cases and age-related healthy individuals were included as the controls, with 136 subjects in each group. Subjects that fulfilled the inclusion criteria were included after giving written and informed consent. Type II diabetics patients on any psychotropic medications (antipsychotics and antidepressants), having neurodegenerative disorders such as Alzheimer's and multi-infarct dementia that can interfere with cognitive assessment, patients on chemotherapy due to malignancy, on drugs such as cannabinoids or opioids, alcohol users, and patients having any thyroid-related problems were excluded from the study. The Hamilton Rating Scale for Depression (HRDS-17) was used for recording depressive symptoms since it consists of a more significant number of somatic symptoms and less affective or cognitive symptoms.

Information related to participants was kept confidential and the study was conducted after taking approval from the ethical review committee of Ziauddin University. Their names and identities were not recorded. Each individual was given a unique identification number. Data analysis was performed using the Statistical Package for Social Sciences (Version 26.0, IBM Corp., Armonk, NY). Descriptive statistics were used for variables such as age, gender, duration of illness, HbA1c, health-care expenditure, social rating, total scores, and depression scores (HRDS-17). The chi-square test and t-test were used to assess the difference. A significance level of 0.05 was considered.

\section{Results}

A total of 272 patients were divided into two groups with 136 patients in the group with diabetes and 136 participants in the control group, the mean age of the group with diabetes was $55.13 \pm 9.10$ years, and in the non-diabetic group, it was $43.25 \pm 12.97$ years with a substantial difference between the groups $(\mathrm{p}<0.001)$. The mean duration of illness in the group with diabetes was $8.51 \pm 7.57$ years. The mean HbA1c in the group with diabetes was $6.91 \pm 1.40$, and in the non-diabetic group, it was $5.78 \pm 0.87$ with a substantial difference between the groups $(\mathrm{p}<0.001)$. The mean health-care expenditure in the group with diabetes was Rs. $7180.88 \pm 5356.20$ /year and in the non-diabetic group was Rs. $5888.23 \pm 4286.18$ /year, with a significant difference between the groups ( $\mathrm{p}=0.029$ ). The mean social rating in the group with diabetes was $164.0 \pm 155.60$, and in the non-diabetic group, it was $124.75 \pm 99.02$, with a significant difference between the groups ( $\mathrm{p}=0.014)$ (Table 1$)$. 


\section{Cureus}

\begin{tabular}{|c|c|c|c|}
\hline Variable & Diabetic (Mean \pm SD) & Non-diabetic (Mean \pm SD) & P-values \\
\hline Age & $55.13 \pm 9.10$ & $43.25 \pm 12.97$ & $<0.001$ \\
\hline \multirow{2}{*}{ Gender } & $55(40.4 \%)$ & $67(49.3 \%)$ & \multirow{2}{*}{0.088} \\
\hline & $81(59.6 \%)$ & 114(83.8\%) & \\
\hline Duration of Illness (years) & $8.51 \pm 7.57$ & $6.73 \pm 4.42$ & 0.018 \\
\hline HbA1c & $6.91 \pm 1.40$ & $5.78 \pm 0.87$ & $<0.001$ \\
\hline Health Care Expenditure (PKR/year) & $7180.88 \pm 5356.20$ & $5888.23 \pm 4286.18$ & 0.029 \\
\hline Social Rating & $164.0 \pm 155.60$ & $124.75 \pm 99.02$ & 0.014 \\
\hline Total Score & $10.44 \pm 7.87$ & $8.77 \pm 7.11$ & 0.069 \\
\hline
\end{tabular}

\section{TABLE 1: Baseline demographics of diabetic versus non-diabetic group}

PKR: Pakistani rupees

No insomnia in the middle of the night was reported in 84 (61.8\%), agitation and disturbed sleep during the night in $48(35.3 \%)$, and waking during the night (except for purposes of voiding) in four (2.9\%) in the group with diabetes ( $\mathrm{p}=0.05)$. Hypochondriasis was not seen in 84 (61.8\%), self-absorption (bodily) in 31 (22.8\%), preoccupation with health in 12 (8.8\%), and frequent complaints in $9(6.6 \%)$ in the group with diabetes $(\mathrm{p}=0.004)$. Loss of weight (according to the weekly patient measurement) was not reported as weight loss in 87 (64.0\%), probable weight loss associated with present illness in 22 (16.2\%), definite (according to the patient) weight loss in seven (5.1\%), and not assessed in 20 (14.7\%) in the group with diabetes (p=0.015) (Table 2).

\begin{tabular}{|c|c|c|c|c|}
\hline \multicolumn{2}{|l|}{ Variable } & Diabetic & Non-diabetic & P-value \\
\hline \multirow{5}{*}{ hopeless, helpless, worthless) } & Absent & 76(55.9\%) & $80(58.8 \%)$ & \multirow{5}{*}{0.889} \\
\hline & $\begin{array}{l}\text { These emotion states indicated } \\
\text { only on questioning }\end{array}$ & 27(19.9\%) & $30(22.1 \%)$ & \\
\hline & $\begin{array}{l}\text { These feeling states } \\
\text { spontaneously reported verbally }\end{array}$ & $17(12.5 \%)$ & 14(10.3\%) & \\
\hline & $\begin{array}{l}\text { Communicates feeling states non- } \\
\text { verbally, i.e. through facial } \\
\text { expression, posture, voice and } \\
\text { tendency to weep }\end{array}$ & $9(6.6 \%)$ & $7(5.1 \%)$ & \\
\hline & $\begin{array}{l}\text { Patient reports virtually only these } \\
\text { feeling states in his/her } \\
\text { spontaneous verbal and non- } \\
\text { verbal communication }\end{array}$ & $7(5.1 \%)$ & $5(3.7 \%)$ & \\
\hline \multirow{6}{*}{ Feelings of Guilt } & Absent & $98(72.1 \%)$ & $91(66.9 \%)$ & \multirow{6}{*}{0.140} \\
\hline & $\begin{array}{l}\text { Self reproach, feels he/she has let } \\
\text { people down }\end{array}$ & 14(10.3\%) & $22(16.2 \%)$ & \\
\hline & $\begin{array}{l}\text { Ideas of guilt or rumination over } \\
\text { past errors or sinful deeds }\end{array}$ & 13(9.6\%) & $19(14.0 \%)$ & \\
\hline & $\begin{array}{l}\text { Present illness is a punishment. } \\
\text { Delusions of guilt }\end{array}$ & $10(7.4 \%)$ & $3(2.2 \%)$ & \\
\hline & $\begin{array}{l}\text { Hears accusatory or denunciatory } \\
\text { voices and/or experiences } \\
\text { threatening visual hallucinations }\end{array}$ & $1(0.7 \%)$ & $1(0.7 \%)$ & \\
\hline & Absent & 122(89.7\%) & 125(91.9\%) & \\
\hline
\end{tabular}




\section{Cureus}

\begin{tabular}{|c|c|c|c|c|c|c|}
\hline \multirow{4}{*}{ Suicide } & Feels life to be useless to live & \multicolumn{2}{|l|}{$8(5.9 \%)$} & \multicolumn{2}{|l|}{$8(5.9 \%)$} & \multirow{4}{*}{0.222} \\
\hline & $\begin{array}{l}\text { Wishes he/she were dead or any } \\
\text { thoughts of possible death to self }\end{array}$ & \multicolumn{2}{|l|}{$5(3.7 \%)$} & \multicolumn{2}{|l|}{$1(0.7 \%)$} & \\
\hline & Ideas or gestures of suicide & \multicolumn{2}{|l|}{$0(0.0 \%)$} & \multicolumn{2}{|l|}{$2(1.5 \%)$} & \\
\hline & Attempts at suicide & \multicolumn{2}{|l|}{$1(0.7 \%)$} & \multicolumn{2}{|l|}{$0(0.0 \%)$} & \\
\hline \multirow{3}{*}{ Insomnia: Early in the Night } & No difficulty falling asleep & \multicolumn{2}{|l|}{$72(52.9 \%)$} & \multicolumn{2}{|c|}{$90(66.2 \%)$} & \multirow{3}{*}{0.056} \\
\hline & $\begin{array}{l}\text { Complains of occasional difficulty } \\
\text { falling asleep, i.e. more than } 1 / 2 \\
\text { hour }\end{array}$ & \multicolumn{2}{|l|}{$52(38.2 \%)$} & \multicolumn{2}{|c|}{$34(25.0 \%)$} & \\
\hline & $\begin{array}{l}\text { Complains of nightly difficulty } \\
\text { falling asleep }\end{array}$ & \multicolumn{2}{|l|}{$12(8.8 \%)$} & \multicolumn{2}{|l|}{$12(8.8 \%)$} & \\
\hline \multirow{3}{*}{ Insomnia: Middle of the Night } & No difficulty & \multicolumn{2}{|l|}{$84(61.8 \%)$} & \multicolumn{2}{|c|}{$97(71.3 \%)$} & \multirow{3}{*}{0.052} \\
\hline & $\begin{array}{l}\text { Patient reports for agitation and } \\
\text { disturbed during the night }\end{array}$ & \multicolumn{2}{|l|}{$48(35.3 \%)$} & \multicolumn{2}{|c|}{$31(22.8 \%)$} & \\
\hline & $\begin{array}{l}\text { Waking during the night-any } \\
\text { getting out of bed rates } 2 \text { (except } \\
\text { for purposes of voiding) }\end{array}$ & \multicolumn{2}{|l|}{$4(2.9 \%)$} & \multicolumn{2}{|l|}{$8(5.9 \%)$} & \\
\hline Variable & & & Diabetic & $\begin{array}{l}\text { Non- } \\
\text { diabetic }\end{array}$ & P-value & \\
\hline \multirow{3}{*}{$\begin{array}{l}\text { Insomnia: Early Hours of the } \\
\text { Morning }\end{array}$} & No difficulty & & $75(55.1 \%)$ & $82(60.3 \%)$ & \multirow{3}{*}{0.320} & \\
\hline & $\begin{array}{l}\text { Waking in early hours of the morn } \\
\text { sleep }\end{array}$ & ig but goes back to & $36(26.5 \%)$ & $39(28.7 \%)$ & & \\
\hline & Unable to fall asleep again if he/sh & gets out of bed & 25(18.4\%) & 15(11.0\%) & & \\
\hline \multirow{5}{*}{ Work and Activities } & No difficulty & & 63(46.3\%) & $84(61.8 \%)$ & & \\
\hline & $\begin{array}{l}\text { Thoughts and feelings of incapaci } \\
\text { related to activities, work or hobb }\end{array}$ & , fatigue or weakness & $56(41.2 \%)$ & $35(25.7 \%)$ & & \\
\hline & $\begin{array}{l}\text { Loss of interest in activity, hobbie } \\
\text { reported by the patient or indirect }\end{array}$ & $\begin{array}{l}\text { or work-either directly } \\
\text { listlessness }\end{array}$ & $10(7.4 \%)$ & $9(6.6 \%)$ & 0.007 & \\
\hline & $\begin{array}{l}\text { Decrease in actual time spent in a } \\
\text { productivity }\end{array}$ & tivities or decrease in & $3(2.2 \%)$ & $8(5.9 \%)$ & & \\
\hline & Stopped working because of pres & nt illness & $4(2.9 \%)$ & $0(0.0 \%)$ & & \\
\hline & Normal speech and thought & & 102(75.0) & $110(80.9 \%)$ & & \\
\hline Retardation (slowness of thought & Slight retardation during the interv & & $26(19.1 \%)$ & $22(16.2 \%)$ & & \\
\hline concentrate decreased motor & Obvious retardation during the int & rview & $4(2.9 \%)$ & $1(0.7 \%)$ & 0.488 & \\
\hline activity) & Interview difficult & & $3(2.2 \%)$ & $3(2.2 \%)$ & & \\
\hline & Complete stupor & & $1(0.7 \%)$ & $0(0.0 \%)$ & & \\
\hline & None & & $83(61.0 \%)$ & $87(64.0 \%)$ & & \\
\hline & Fidgetiness & & $42(30.9 \%)$ & $34(25.0 \%)$ & & \\
\hline Agitation & Playing with hands, hair, etc & & $5(3.7 \%)$ & $10(7.4 \%)$ & 0.231 & \\
\hline & Moving about, can’t sit still & & $6(4.4 \%)$ & $3(2.2 \%)$ & & \\
\hline & Hand wringing, nail biting, hair-pu & ng, biting of lips & $0(0.0 \%)$ & $2(1.5 \%)$ & & \\
\hline & No difficulty & & $69(50.7 \%)$ & $68(50.0 \%)$ & & \\
\hline & Subjective tension and irritability & & $35(25.7 \%)$ & $38(27.9 \%)$ & & \\
\hline Anxiety psychic & Worrying about minor matters & & $22(16.2 \%)$ & 25(18.4\%) & 0.713 & \\
\hline & Apprehensive attitude apparent in & ace or speech & $7(5.1 \%)$ & $3(2.2 \%)$ & & \\
\hline
\end{tabular}




\section{Cureus}

\begin{tabular}{|c|c|c|c|c|}
\hline & Fears expressed without questioning & $3(2.2 \%)$ & $2(1.5 \%)$ & \\
\hline \multirow{5}{*}{ Anxiety Somatic } & Absent & $69(50.7 \%)$ & 79(58.1\%) & \multirow{5}{*}{0.411} \\
\hline & Mild & $42(30.9 \%)$ & $41(30.1 \%)$ & \\
\hline & Moderate & $23(16.9 \%)$ & $14(10.3 \%)$ & \\
\hline & Severe & $2(1.5 \%)$ & $2(1.5 \%)$ & \\
\hline & Incapacitating & $0(0.0 \%)$ & $0(0.0 \%)$ & \\
\hline \multirow{3}{*}{$\begin{array}{l}\text { Somatic Symptoms Gastro- } \\
\text { Intestinal }\end{array}$} & None & $97(71.3 \%)$ & $92(67.6 \%)$ & \multirow{3}{*}{0.272} \\
\hline & $\begin{array}{l}\text { Loss of appetite but eating without staff encouragement. } \\
\text { Heavy feelings in abdomen }\end{array}$ & $31(22.8 \%)$ & $40(29.4 \%)$ & \\
\hline & $\begin{array}{l}\text { Difficulty eating without staff urging. Requests or requires } \\
\text { laxatives or medication for bowels or medication for } \\
\text { gastro-intestinal symptoms }\end{array}$ & $8(5.9 \%)$ & $4(2.9 \%)$ & \\
\hline \multirow{3}{*}{ General Somatic Symptoms } & None & $74(54.4 \%)$ & $81(59.6 \%)$ & \multirow{3}{*}{0.362} \\
\hline & $\begin{array}{l}\text { Heaviness in limbs or head. Backaches, headaches, } \\
\text { muscle aches. Loss of energy and fatigability }\end{array}$ & $61(44.9 \%)$ & $52(38.2 \%)$ & \\
\hline & Any clear-cut symptom & $1(0.7 \%)$ & $3(2.2 \%)$ & \\
\hline \multirow{3}{*}{ Genital Symptoms } & Absent & $102(75.0 \%)$ & $111(81.6 \%)$ & \multirow{3}{*}{0.414} \\
\hline & Mild & $31(22.8 \%)$ & $23(16.9 \%)$ & \\
\hline & Severe & $3(2.2 \%)$ & $2(1.5 \%)$ & \\
\hline \multirow{4}{*}{ Hypochondriasis } & Not present & $84(61.8 \%)$ & $108(79.4 \%)$ & \multirow{4}{*}{0.004} \\
\hline & Self-absorption (bodily) & $31(22.8 \%)$ & $14(10.3 \%)$ & \\
\hline & Preoccupation with health & $12(8.8 \%)$ & $4(2.9 \%)$ & \\
\hline & Frequent complaints, requests & $9(6.6 \%)$ & $10(7.4 \%)$ & \\
\hline \multirow{4}{*}{$\begin{array}{l}\text { Loss of Weight (rate either } \mathrm{a} \text { or } \mathrm{b} \text { ) } \\
\text { (A: According to the patient) }\end{array}$} & Absence of loss of weight & $87(64.0 \%)$ & $107(78.7 \%)$ & \multirow{4}{*}{0.015} \\
\hline & possible weight loss related with present illness & $22(16.2 \%)$ & $7(5.1 \%)$ & \\
\hline & Definite (according to patient) weight loss & $7(5.1 \%)$ & $5(3.7 \%)$ & \\
\hline & Not assessed & $20(14.7 \%)$ & $17(12.5 \%)$ & \\
\hline \multirow{4}{*}{$\begin{array}{l}\text { (B: According to weekly patient: } \\
\text { measurement) }\end{array}$} & Less than $1 \mathrm{lb}$ weight loss in week & $84(61.8 \%)$ & $96(70.6 \%)$ & \multirow{4}{*}{0.493} \\
\hline & Greater than $1 \mathrm{lb}$ welght loss in a week & $5(3.7 \%)$ & $4(2.9 \%)$ & \\
\hline & Greater than $2 \mathrm{lb}$ weight loss in a week & $1(0.7 \%)$ & $1(0.7 \%)$ & \\
\hline & Not assessed & $46(33.8 \%)$ & $35(25.7 \%)$ & \\
\hline \multirow{3}{*}{ Insight } & Acknowledges being depressed and ill & $73(53.7 \%)$ & $73(53.7 \%)$ & \multirow{3}{*}{0.321} \\
\hline & $\begin{array}{l}\text { Acknowledges IIIness but attributes cause to bad food, } \\
\text { climate, overwork, etc. }\end{array}$ & $29(21.3 \%)$ & $20(14.7 \%)$ & \\
\hline & Denies being ill at all & $34(25.0 \%)$ & $42(31.6 \%)$ & \\
\hline
\end{tabular}

TABLE 2: Hamilton Depression Rating Scale (HAM-D) between diabetic and non-diabetic groups

\section{Discussion}

According to the present study results, anxiety and depressive symptoms were observed higher among diabetics than controls. Likewise, in the analysis of studies regarding anxiety/depression, a higher prevalence has been reported among people with diabetes than controls [15-17]. In this regard, a study observed that a high probability existed in patients with diabetes for developing anxiety or depression [18]. 
Even though the association of anxiety and depression with diabetes mellitus has long been stated, yet the frequency of symptoms is rapidly increasing worldwide [19-21]. As a result, it is necessary to observe the presence of such symptoms among people with diabetes, especially to improve compliance to treatment, which will result in a positive impact on diabetic control [22-23]. For this purpose, a study conducted to determine the frequency of anxiety and depression among 820 patients with type II diabetes using the HAMD discovered that $48.27 \%$ and $55.1 \%$ of the patients with diabetes in the study were suffering from depression and anxiety, respectively. The main reasons reported for the cause of anxiety issues were attributed to occupation and complications in diabetes while glucose levels and difficulties in diabetes were linked to depression. A highly significant factor for both anxiety and depression was diabetic complications [24].

In yet another study evaluating the relationship between major depression and the glucose control index among type II diabetics, from 134 patients, using HAM-D, a significantly higher depressive score was reported among patients with diabetes having hypertension $(\mathrm{p}=0.001)$, asthma $(\mathrm{p}-0.01)$, and on insulin treatment $(p=0.005)[25]$. Similar findings were reported in our study as well. However, in contrast to our research, the above research reported an insignificant association between the level of depressive symptoms and $\mathrm{HbA} 1 \mathrm{c}$ among type II diabetes patients.

Another study determining the prevalence of psychiatric morbidity among diabetic patients using standardized HAM-D scales for depression and anxiety reported that approximately $84 \%$ of patients had comorbid depression in which females were found to have a higher percentage of anxiety and depression. Besides, the severity of depression was also elevated among females. Genital symptoms were reported higher among males, whereas somatic symptoms were common among females [26]. However, in our study, we reported the frequencies among the diabetic and control groups, including males and females, without analyzing them separately. Overall, an insignificant association was reported in terms of depression in type II diabetics in males and females. Another study determined the frequency of depression among type II diabetics and reported that $38.75 \%$ of patients suffered from depression, among which $48.33 \%$ were found to have severe depression. However, an insignificant association was reported between depression in type II diabetics with sociodemographic factors like age $(p=0.92)$, gender $(p=0.25)$, education $(p=94)$, and marital status $(\mathrm{p}=0.064)$ [27]. Similarly, in another study, using the HAM-D scale, $34 \%$ of type II diabetics were found to have depression and anxiety. The above studies reported that diabetic patients that were depressed were severely affected in their daily routine activities [28]. Likewise in our study as well, depressed patient's daily activities were severely affected $(\mathrm{p}=0.007)$. In accordance with our study findings, yet another study reported around half of type II diabetics to have depression with significant deficits in cognitive function, affected sleep, and loss of weight [29].

\section{Limitations of the study}

Although the study evaluated several aspects of the type of diabetes associated with depression and anxiety and its effect on patients' quality of life, it was not immune to selection and recall biases. In addition to selection and recall bias, the study was conducted in a single center, thereby being performed on patients belonging to a specific socio-economic class. Socio-economic status and family support were also undetermined in the study. Another limitation of our study was the small sample size, therefore, we recommend large-scale prospective studies in our population to assess the impact of depression and anxiety in diabetic patients.

\section{Conclusions}

According to the results of the study, most of the patients with diabetes in the study reported a significant effect on their quality of life based on social rating and health-care expenditure, and they experienced depressive symptoms more frequently than non-diabetics. However, in terms of social stressors and depressive symptoms/illness, most of the stressors did not report significant differences between patients with diabetes and the controls. Insomnia in the middle of the night affected their work and activities; hypochondriasis and loss of weight were found to be substantially higher among patients with diabetes as compared with controls.

\section{Additional Information \\ Disclosures}

Human subjects: Consent was obtained by all participants in this study. Ethical review committee of Ziauddin University issued approval 0521018SYMED. Animal subjects: All authors have confirmed that this study did not involve animal subjects or tissue. Conflicts of interest: In compliance with the ICMJE uniform disclosure form, all authors declare the following: Payment/services info: All authors have declared that no financial support was received from any organization for the submitted work. Financial relationships: All authors have declared that they have no financial relationships at present or within the previous three years with any organizations that might have an interest in the submitted work. Other relationships: All authors have declared that there are no other relationships or activities that could appear to have influenced the submitted work. 


\section{References}

1. Kaur G, Tee GH, Ariaratnam S, Krishnapillai AS, China K: Depression, anxiety, and stress symptoms among diabetics in Malaysia: a cross-sectional study in an urban primary care setting. BMC Fam Pract. 2013, 14:69. 10.1186/1471-2296-14-69

2. Bădescu SV, Tătaru C, Kobylinska L, Georgescu EL, Zahiu DM, Zăgrean AM, Zăgrean L: The association between diabetes mellitus and depression. J Med Life. 2016, 9:120-125.

3. Moulton $\mathrm{CD}$, Pickup JC, Ismail K: The link between depression and diabetes: the search for shared mechanisms. Lancet Diabetes Endocrinol. 2015, 3:461-471. 10.1016/S2213-8587(15)00134-5

4. Mirzaei MA, Daryafti HA, Fallahzadeh HO, Azizi BA: Evaluation of depression, anxiety and stress in diabetic and non-diabetic patients. JSSU. 2016, 24:387-397.

5. Nawaz MS, Shah KU, Rashid HU, et al.: Factors associated with anxiety in type 2 diabetes mellitus patients in Pakistan. Int J Diabetes Dev Ctries. 2018, 38:298-304. 10.1007/s13410-017-0591-0

6. Atif K, Khan HU, Ullah MZ, Shah FS, Latif A: Prevalence of anxiety and depression among doctors; the unscreened and undiagnosed clientele in Lahore, Pakistan. Pak J Med Sci. 2016, 32:294-298. 10.12669/pjms.322.8731

7. Rajput R, Gehlawat P, Gehlan D, Gupta R, Rajput M: Prevalence and predictors of depression and anxiety in patients of diabetes mellitus in a tertiary care center. Indian J Endocrinol Metab. 2016, 20:746-751. 10.4103/2230-8210.192924

8. Fisher L, Gonzalez JS, Polonsky WH: The confusing tale of depression and distress in patients with diabetes: a call for greater clarity and precision. Diabet Med. 2014, 31:764-772.

9. Ganasegeran K, Renganathan P, Manaf RA, Al-Dubai SA: Factors associated with anxiety and depression among type 2 diabetes outpatients in Malaysia: a descriptive cross-sectional single-centre study. BMJ Open. 2014, 4:004794. 10.1136/bmjopen-2014-004794

10. Petrak F, Baumeister H, Skinner TC, Brown A, Holt RIG: Depression and diabetes: treatment and health-care delivery. Lancet Diabetes Endocrinol. 2015, 3:472-485. 10.1016/S2213-8587(15)00045-5

11. Derakhshanpour F, Vakili MA, Farsinia M, Mirkarimi K: Depression, and quality of life in patients with type 2 diabetes. Iran Red Crescent Med J. 2015, 17:1-19. 10.5812/ircmj.17(5)2015.27676

12. Snoek FJ, Bremmer MA, Hermanns N: Constructs of depression and distress in diabetes: time for an appraisal. Lancet Diabetes Endocrinol. 2015, 3:450-460. 10.1016/S2213-8587(15)00135-7

13. Kelly SJ, Ismail M: Stress and type 2 diabetes: a review of how stress contributes to the development of type 2 diabetes. Annu Rev Public Health. 2015, 36:441-462. 10.1146/annurev-publhealth-031914-122921

14. Detka J, Kurek A, Basta-Kaim A, Kubera M, Lasoń W, Budziszewska B: Neuroendocrine link between stress, depression and diabetes. Pharmacol Rep. 2013, 65:1591-1600. 10.1016/s1734-1140(13)71520-2

15. Toroski M, Rajabzadeh R, Niyazi M, Hayati H, Shakeri HS, Rezapour M, Hosseini SH: The relationship between socioeconomic and therapeutic factors with the quality of life among the patient's type II diabetes. Journal of Pharmacoeconomics and Pharmaceutical Management. 2016, 2:19-24.

16. Deschênes SS, Burns RJ, Graham E, Schmitz N: Prediabetes, depressive and anxiety symptoms, and risk of type 2 diabetes: a community-based cohort study. J Psychosom Res. 2016, 89:85-90. 10.1016/j.jpsychores.2016.08.011

17. Naic Naicker K, Johnson JA, Skogen JC, Manuel D, Øverland S, Sivertsen B, Colman I: Type 2 diabetes and comorbid symptoms of depression and anxiety: longitudinal associations with mortality risk. Diabetes Care. 2017, 40:352-358. 10.2337/dc16-2018

18. Pouwer F, Nefs G, Nouwen A: Adverse effects of depression on glycemic control and health outcomes in people with diabetes: a review. Endocrinol Metab Clin North Am. 2013, 42:529-544. 10.1016/j.ecl.2013.05.002

19. Sweileh WM, Abu-Hadeed HM, Al-Jabi SW, Zyoud SH: Prevalence of depression among people with type 2 diabetes mellitus: a cross sectional study in Palestine. BMC Public Health. 2014, 14:163. 10.1186/1471-245814-163

20. Deuschle M: Effects of antidepressants on glucose metabolism and diabetes mellitus type 2 in adults . Curr Opin Psychiatry. 2013, 26:60-65. 10.1097/YCO.0b013e32835a4206

21. Siddiqui S, Jha S, Waghdhare S, Agarwal NB, Singh K: Prevalence of depression in patients with type 2 diabetes attending an outpatient clinic in India. Postgrad Med J. 2014, 90:552-556. 10.1136/postgradmedj2014-132593

22. Lewko J, Zarzycki W, Krajewska-Kułak E: Relationship between the occurrence of symptoms of anxiety and depression, quality of life, and level of acceptance of illness in patients with type 2 diabetes. Saudi Med J. 2012, 33:887-894

23. Wu SF, Young LS, Yeh FC, Jian YM, Cheng KC, Lee MC: Correlations among social support, depression, and anxiety in patients with type-2 diabetes. J Nurs Res. 2013, 21:129-138. 10.1097/jnr.0b013e3182921fe1

24. Tovilla-Zárate C, Juárez-Rojop I, Peralta Jimenez Y, et al.: Prevalence of anxiety and depression among outpatients with type 2 diabetes in the Mexican population. PLoS One. 2012, 7:36887. 10.1371/journal.pone.0036887

25. Rezvanfar MR, Salehi B, Rafiee M, Shirian F: Correlation of HbA1c and major depressive disorder in type 2 diabetic patients. Iranian Journal of Diabetes and Obesity. 2010, 2:16-19.

26. Chaudhry R, Mishra P, Mishra J, Parminder S, Mishra BP: Psychiatric morbidity among diabetic patients: a hospital-based study. Ind Psychiatry J. 2010, 19:47-49. 10.4103/0972-6748.77637

27. Mushtaque A, Gulati R, Hossain MM, Azmi SA: Prevalence of depression in patients of type 2 diabetes mellitus: a cross sectional study in a tertiary care centre. Diabetes Metab Syndr. 2016, 10:238-241. 10.1016/j.dsx.2016.06.016

28. Chaudhary R, Kumar P, Chopra A, Chabbra S, Singh P: Comparative study of psychiatric manifestations among type I and type ii diabetic patients. Indian J Psychol Med. 2017, 39:342-346. 10.4103/IJPSYM.IJPSYM_35_17

29. Degmecić D, Bacun T, Kovac V, Mioc J, Horvat J, Vcev A: Depression, anxiety and cognitive dysfunction in patients with type 2 diabetes mellitus--a study of adult patients with type 2 diabetes mellitus in Osijek, 


\section{Cureus}

Croatia. Coll Antropol. 2014, 38:711-716. 